\section{Turismo como Fator de Decisão no Planejamento de Empresas Aéreas Regionais Brasileiras}

Tourism as a Decision Factor in Planning among Brazilian Regional Airlines

\section{Flávio José Valente Guilherme Lohmann}

RESUMO: Nos últimos anos, o número de destinos turísticos servidos por linhas aéreas domésticas regionais decresceu significativamente no Brasil. Apesar das iniciativas de várias empresas aéreas em criar novas linhas, muitas não perduram. A fim de melhor entender os motivos desses insucessos, este artigo analisa, com base em dados secundários, o contexto das empresas aéreas regionais brasileiras, apresentando os conceitos de planejamento de linhas aéreas regulares propostos pela literatura; e com base em dados primários, a partir de questionários enviados às empresas aéreas regionais, a influência de diversos fatores, notadamente o turístico, no processo de planejamento de linhas aéreas. Como resultado dessa pesquisa, é proposto um modelo sistêmico para o planejamento de linhas regulares de empresas aéreas regionais.

\footnotetext{
1. Bacharel em Turismo pela Universidade Estácio de Sá - RJ, especialista em Gestão Estratégica de Marketing pela PUC-MG e mestre em Turismo e Hotelaria pela UNIVALI-SC. Atualmente, é professor de Agenciamento e Transportes na PUC-MG. Atua desde 1984 como empresário na área de agenciamento, tendo também atuado como representante comercial de linha aérea regional por dez anos. Contato: Rua Rio Grande do Sul, 1091/1001 - 37701-001 - Poços de Caldas-MG; e-mail: fjvalente@pocosnet.com.br.

2. Engenheiro de Transportes pela L'FRI e mestre em Ciências em Engenharia de Transportes pela COPPE/UfRJ. Atualmente, é bolsista da CAPES e faz doutorado em Turismo na Victoria University of Wellington (Nova Zelândia). Tem publicados pela Editora Aleph os livros Transportes turísticos e Transporte aéreo e turismo: gerando desenvolvimento socioeconômico. Contato: Tourism Management - Victoria University of Wellington - PO Box 600 - Wellington - Nova Zelândia; e-mail gui@guilohmann.com.
}

PALAVRAS-CHAVE: empresas aéreas regionais; turismo; planejamento de linhas aéreas.

ABSTRACT: In the last few years the number of tourist destinations served by domestic regional airlines has significantly decreased in Brazil. In spite of the initiatives of several airlines in launching new air routes, many of them do not succeed. In order to better understand the reasons for these failures, this article analyses, using secondary data, the context of Brazilian regional airlines and presents the concepts of air route planning proposed by the literature. Primary data, using questionnaires sent to regional airlines, was collected with the purpose of analysing the influence of various factors, notably tourism, on the route planning process. As a result of this research, a systemic model for air route planning at the regional scale is proposed.

KEYWORDS: regional airlines; tourism; air route planning.

\section{Introdução}

O transporte aéreo é elemento fundamental para o estágio atual de desenvolvimento do turismo mundial (Palhares, 2001; 2002). Em diferentes escalas geográficas, as empresas aéreas contribuem para a existência de um fluxo turístico intercontinental, internacional, doméstico e regional.

Ainda que no Brasil boa parte dos principais destinos turísticos se encontre em grandes centros urbanos, com grande acessibilidade multimodal com os demais centros do país e do exterior, muitas cidades de médio e pequeno porte, sobretudo no interior, dependem quase exclusivamente das ligações aérea e rodoviária para a sua integração com o restante do país. No caso específico do transporte aéreo, as pequenas e médias cidades, bem como alguns resorts turísticos, têm nas ligações com os grandes aeroportos nacionais não só uma forma de permitir a chegada de turistas domésticos e internacionais, mas também de garantir que seus habitantes tenham acesso à malha aeroviária do país e do exterior.

Em muitas partes do mundo, o transporte aéreo regional tem se mostrado o segmento de maior crescimento na indústria do transporte aéreo (Donne, 2001; Graham, 1997; Graham \& Guyer, 2000; Hanlon, 1992). Sua importância e dinamismo podem ser evidenciados de várias formas. No que diz respeito aos fabricantes de aeronaves, pôde-se acompanhar nos últimos anos a crescente disputa, inclusive na esfera da Organização Mundial do Comércio, entre a Embraer e a Bombardier, os maiores fabricantes mundiais de jatos regionais. Em relação às empresas aéreas brasileiras, seu número dobrou de cinco, no período entre 
1975-1992 (Nordeste, Rio-Sul, TABA, TAM e vOTEC, posteriormente Brasil Central), para dez em 2003. Com a reestruturação do Sistema de Transporte Aéreo Regular em 1992, por meio da Portaria no 687/GM5, de 15 de setembro, o número de assentos/quilômetro saltou de dois bilhões para mais de onze bilhões, em 2000 (BNDES, 2002).

Apesar disso, é possível identificar diversas iniciativas de empresas aéreas e municípios em que as linhas aéreas regionais implantadas não subsistiram. A Figura 1 mostra a evolução do número de localidades servidas pelo transporte aéreo regional entre 1960 e 2002 . Nela podem se verificar três fases distintas: $1960-1975 ; 1975-2000 ; 2000-2002$

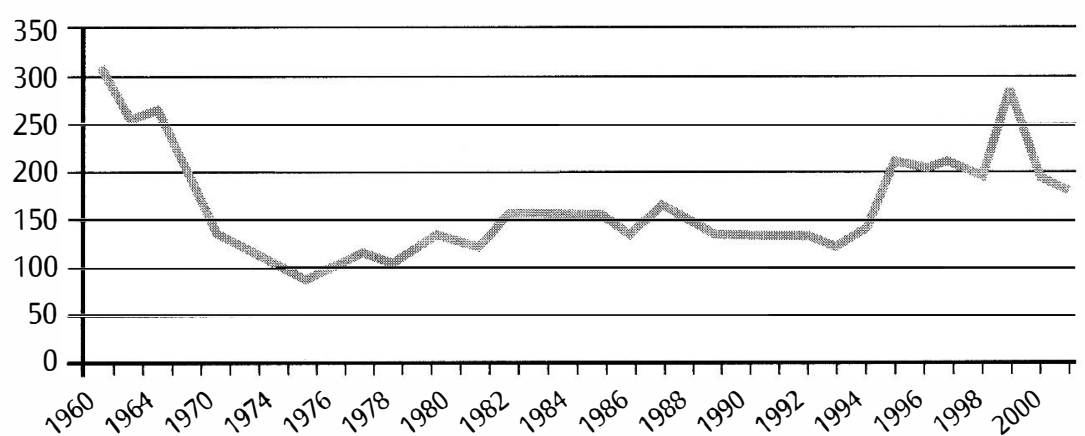

Figura 1. Evolução do número de localidades servidas por transporte aéreo regional no Brasil - 1960-2002

Fonte: BNDES, 2002.

A primeira fase, compreendida entre 1960 e 1975, possui brusca queda no número de localidades servidas por causa dos cortes orçamentários do governo na Rede de Integração Nacional (RIN), programa este que concedia subsídios especiais nas rotas consideradas de baixo e médio potencial de tráfego, e também por causa da introdução de aeronaves maiores, fazendo com que as empresas priorizassem rotas mais rentáveis.

A segunda fase, entre 1975 e 2000, se verifica um crescimento inconstante até 1994, quando, em 1995, se iniciou um processo de expansão mais acentuado. O crescimento, a partir da metade da década de 1990, está associado ao processo de flexibilização do setor, que não só permitiu a entrada de novas empresas aéreas no mercado, mas também incentivou a criação de novas linhas, com alteração nas regras da suplementação tarifária. Segundo Trigo (2000), em
11 de novembro de 1975, o governo brasileiro criou, por meio do Decreto no 76.590, os Sistemas Integrados de Transportes Aéreos Regionais - SITAR, para servir às áreas mais remotas do país e às pequenas e médias localidades em que o transporte de superfície era inexistente ou precário. Para tanto fazia-se uso de aviões de menor porte e com operação mais simplificada, que utilizavam pistas curtas e de terra batida. A criação do SITAR fez com que muitas linhas abandonadas fossem subsidiadas por verbas extraídas da operação das principais rotas nacionais. De acordo com a política de competição controlada, cinco novas empresas passaram a existir, cada uma delas operando em uma base territorial definida, a saber:

- Rio-Sul: Estados do Sul, Rio de Janeiro, litoral de São Paulo e Espírito Santo;

- TABA: Estados da Amazônia e norte do Mato Grosso;

- tam: Mato Grosso do Sul, partes de São Paulo e Mato Grosso;

- votec: Estados de Goiás, Distrito Federal, partes do Pará, Minas Gerais e Mato Grosso;

- Nordeste: Estados do Nordeste, partes do Maranhão, Espírito Santo e Minas Gerais.

Ao longo do tempo, houve um descompasso entre os princípios propostos e a realidade das empresas e do mercado. Isso pode ser observado nas propostas iniciais de interligar as linhas dos SITAR às linhas-tronco, e no princípio de utilização de aeronaves menores que foram, aos poucos, abandonadas.

A terceira e última fase dá-se a partir do ano 2000, com a queda no número de localidades servidas, que retornou ao patamar anterior a 1998. Essa fase está relacionada não só às questões econômicas e cambiais do país, mas também, em parte, à diminuição no valor total arrecadado com o Adicional Tarifário. Cobrado nas passagens das linhas mais rentáveis, o Adicional Tarifário, cujo valor é de 3\%, é repassado como forma de subsídio cruzado para as empresas que operam linhas com baixa demanda. Como desde 1999 as grandes empresas nacionais têm obtido na justiça o direito de não mais pagarem tais subsídios, o total arrecadado com a suplementação tarifária caiu de mais de $\mathrm{R} \$ 50$ milhões, em 1997, para pouco mais de R\$ 10 milhões em 2001. Por conta disso, segundo o BNDES (2002:4),

a metodologia até então vigente não levava em consideração um índice de desempenho para cada linha operada e permitia às empresas efetuar políticas de caixa, pois muitas vezes era estipulada uma ligação mesmo sem uma demanda condizente com a sua implantação para, dessa forma, receber a suplementação. 
Com a diminuição dos subsídios cruzados, o cenário atual do planejamento de linhas aéreas regionais parece que irá se focar mais em direção à viabilidade real e potencial da demanda. Dentre os fatores que podem proporcionar grande estímulo na geração de demanda está o turismo. Muitas vezes, no entanto, as discussões sobre o relacionamento entre o turismo e o transporte aéreo acontecem sem que se passe por questões conceituais que unem essas atividades. De acordo com Debbage (2002), poucas pesquisas científicas têm sido produzidas no sentido de discutir conceitualmente essa interface e suas implicações no ambiente do planejamento das ligações aéreas, tanto por parte das empresas aéreas quanto por parte dos destinos turísticos.

O presente artigo tem como objetivo, portanto, analisar os fatores que influenciam o planejamento das empresas aéreas regionais brasileiras no que se refere à implantação de linhas regulares sob a perspectiva da relação transporte-turismo. Para tanto, identificou-se o perfil geral das empresas aéreas que operam vôos regulares de atuação regional no Brasil, levantando e analisando os aspectos utilizados pertinentes ao fator turístico, além de estabelecer relação entre os outros fatores empregados no processo de planejamento de linhas, atribuindo-lhes pesos numa escala de influência nas decisões tomadas. De caráter indutivo, essa pesquisa termina apresentando um modelo sistêmico para o planejamento de linhas aéreas regionais.

Além desta introdução, o artigo está estruturado em mais quatro outras seções, que incluem revisão conceitual; metodologia; análise dos dados coletados e considerações finais.

\section{Revisão conceitual: transporte aéreo regional, planejamento de linhas aéreas e turismo}

\section{Transporte aéreo regional}

Ainda que o conceito de transporte aéreo regional possa variar de país para país, de forma genérica ele está associado às empresas que operam aeronaves com determinada capacidade de passageiros (20-120 assentos) e fazendo uso de uma força motriz com tecnologia específica (notadamente turboélices e jatos regionais - regional jets - $\mathrm{RJ}$ ) (Hanlon, 1992). Relacionada a esses fatores tecnológicos e de capacidade, está a própria autonomia das aeronaves empregadas, menores que os jatos, uma vez que seu uso é destinado a viagens de pequeno e médio alcance. No entanto, com o advento dos jatos regionais ERJ145 e CRJ200, que proporcionam maior alcance de vôo (em torno de três mil quilômetros), muitas empresas aéreas regionais, notadamente nos Estados Unidos e na Europa, passaram a interligar destinos com grandes distâncias (Graham, 1997).

Nos Estados Unidos, por exemplo, as empresas aéreas de passageiros são divididas em três categorias: majors (com receitas operacionais acima de um bilhão de dólares), nacionais (com receitas operacionais entre cem milhões e um bilhão de dólares) e regionais (com receitas operacionais até cem milhões de dólares). Por sua vez, as empresas regionais são subdivididas em outros três grupos, também em função de suas receitas operacionais e da capacidade de suas aeronaves: grandes (vinte a cem milhões de dólares), médias (abaixo de vinte milhões de dólares) e pequenas (abaixo de vinte milhões de dólares, operando aeronaves com menos de 61 assentos) (ATA, 2001).

Na Europa, assim como nos EUA, as empresas aéreas regionais têm-se caracterizado também pela operação em aeroportos regionais (Donne, 2001; Graham \& Guyer, 2000). Tais aeroportos geralmente provêm ligações diretas entre pequenos e médios centros e entre estes e as capitais e grandes centros urbanos. A grande vantagem oferecida no primeiro caso é que os vôos diretos não precisam passar pelos hubs dos principais aeroportos, geralmente bastante congestionados.

No Brasil, entre os anos de 1975 e 1999, o termo “aviação regional” representou as linhas e serviços aéreos que atendiam localidades de médio e baixo potencial de tráfego. A partir do ano 2000, o Departamento de Aviação Civil DAC extinguiu a distinção entre empresas de "âmbito" nacional e regional, sendo todas classificadas como empresas domésticas de transporte aéreo regular. No entanto, os parágrafos $1^{\circ}$ e $2^{\circ}$ do artigo $6^{\circ}$ da Portaria $n^{\circ}$ 569/GC5, de 5/7/2000, classifica as linhas aéreas domésticas como nacionais (aquelas que ligam as capitais e as cidades com mais de um milhão de habitantes), regionais (aquelas que efetuam a ligação entre as demais cidades com aquelas servidas pelas linhas aéreas nacionais) e especiais (aquelas que ligam diretamente dois aeroportos centrais - Santos Dumont, Congonhas e Pampulha - ou um aeroporto central e o aeroporto da Capital Federal - Juscelino Kubitschek). De acordo com o parágrafo 2 do artigo 6 da Portaria n 676/GC5, de 20/10/1999, as linhas aéreas domésticas regionais se caracterizam por serem afluentes ou complementares às linhas aéreas domésticas nacionais.

Geralmente, as empresas aéreas regionais - neste artigo, se referem às empresas que no Brasil operam linhas de âmbito regional - podem funcionar de duas formas. A primeira, como subsidiárias das empresas nacionais, em que efetuam vôos de menor alcance na malha aérea da empresa principal (linhas troncoalimentadoras). A segunda, de forma independente, ainda que muitas vezes em parceria com as grandes empresas nacionais. Como exemplo de empresas regionais subsidiárias teve-se, durante muitos anos, os casos da Nordeste e da Rio-Sul, 
ambas do grupo Varig. Já as empresas independentes (ver Tabela 1) podem, eventualmente, ter parcerias e alianças, tais como uso comum de sistemas de reservas por computador - CRS - e programas de milhagem (Hanlon, 1992), code-share, marketing e vendas, uso de salas vip etc. Esse foi o caso, por exemplo, do acordo assumido entre a Varig e a Rico Linhas Aéreas em setembro de 2003. Nele, a Varig passou a transportar seus passageiros até Manaus, onde são distribuídos para as demais cidades dos estados do Norte do Brasil pela Rico.Segundo Doganis (2001), em alguns casos, as grandes empresas estabelecem franquias a serem operadas por empresas regionais.

\section{0 planejamento de linhas aéreas regulares: uma visão sistêmica}

Por meio de uma análise sistêmica, pode-se considerar uma empresa aérea um subsistema aberto e em constante intercâmbio com fluxos contínuos de entradas (input) e saídas (output) de recursos. A Figura 2 contempla, através do modelo proposto por Fryszman (1990), algumas macrovariáveis básicas que explicam a dinâmica do sistema de planejamento do transporte aéreo.

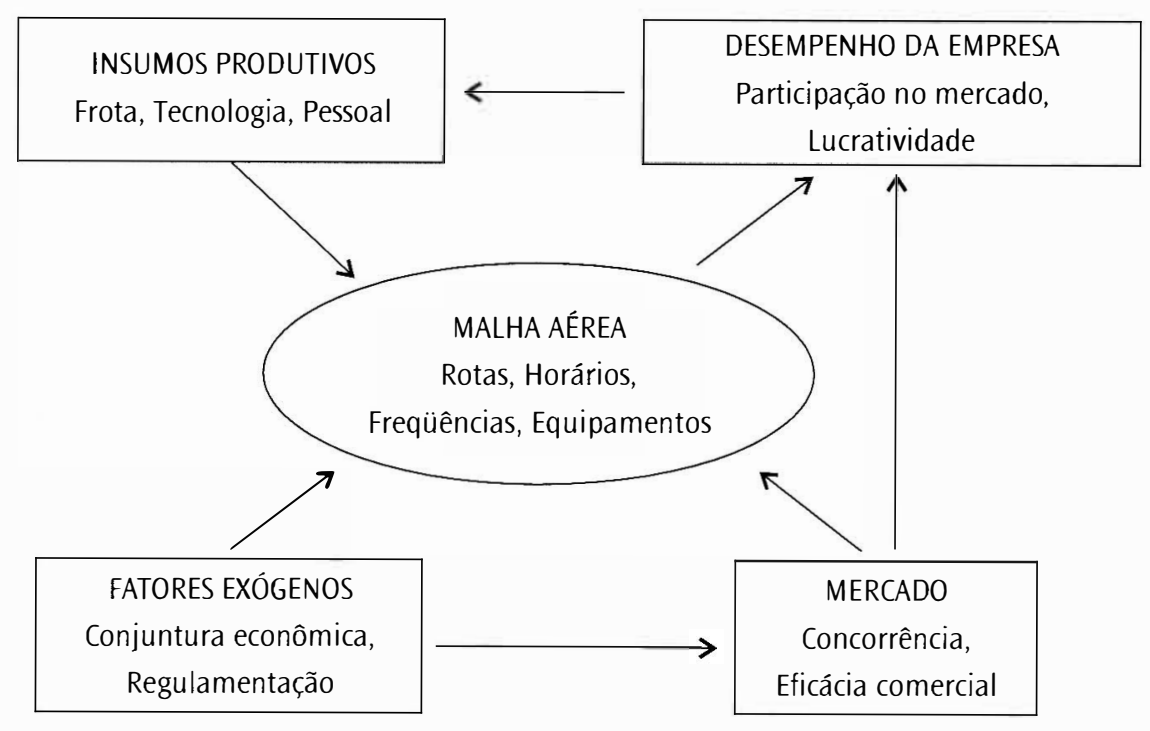

Figura 2. Visão sistêmica do planejamento de linhas de empresas aéreas

Fonte: Fryszman, 1990.
Os insumos produtivos referem-se ao pessoal e equipamentos (frota de aeronaves) de que a empresa deve dispor para realizar sua atividade-fim: transportar. A frota é um dos principais aspectos, pois as características operacionais dos equipamentos podem influenciar questões econômicas e financeiras, além de outras. Os fatores exógenos dizem respeito à conjuntura econômica do país ou região e regulamentações por parte do governo no que se refere a tarifas, concessão de linhas, entre outros. O mercado representa todo o ambiente comercial no qual a empresa está inserida, compreendendo: passageiros (clientes), concorrentes, além de aspectos relacionados à propaganda e à publicidade. O mercado é, muitas vezes, condicionado por fatores econômicos sobre os quais a empresa não tem controle, considerados aqui fatores exógenos. Já o desempenho da empresa é tido como parâmetro de controle e realimentação do modelo, uma vez que a empresa fixa metas de participação de mercado e lucro que, não sendo atingidas, exigirão revisão na sua estratégia de atuação. A lucratividade da empresa é um aspecto gerador de capital necessário à aquisição de recursos e à expansão das atividades, dentro de uma conjuntura de mercado favorável. Por fim, tem-se a malha aérea, que é vista como a face externa da empresa. Todas as áreas funcionais da empresa gravitam em torno do cumprimento dos vôos programados. É dependente dos insumos disponíveis (principalmente frota), das condições de mercado e de fatores de regulamentação, condicionando diretamente o desempenho da empresa. Percebe-se que são relações de causa-efeito, sendo a decisão de implantar novas linhas, e de como fazê-lo, um grande desafio organizacional.

Fatores influenciadores do planejamento de linhas aéreas regulares

Silva et al. (2000), numa visão pragmática, colocam que o problema de planejamento de linhas aéreas, tradicionalmente, resume-se à identificação da maneira mais eficiente de atender à demanda de uma determinada linha, a partir de uma adequada oferta do produto viagem (assentos). Schäffler (1995), olhando para a estrutura do tráfego aéreo regional, apresenta outros fatores influenciadores: políticos (regulamentações); infra-estrutura em terra e no ar; estrutura dos operadores; estrutura de fabricantes e avanços tecnológicos.

Na realidade, o que se observa é uma conjunção e mútua interdependência de fatores influenciadores. Como exemplo disso, Silveira (2003) afirma que, ao tomar decisões quanto ao dimensionamento e composição de suas frotas de aeronaves, as companhias aéreas se valem muitas vezes de estudos para identificar e quantificar a demanda nos mercados onde atuam - e naqueles onde pretendem atuar. Tudo isso tendo como pano de fundo hipóteses e cenários sobre a situação 
econômica interna e externa do país. Claro está que incertezas sobre os rumos da economia, bem como deficiências na identificação dos mercados (inclusive os novos) e seu mau dimensionamento, podem levar a decisões desastrosas de compra e/ou arrendamento de aeronaves, e sua alocação aos vôos, o que, em certo sentido, explica o excesso de capacidade oferecido pelas transportadoras. Entretanto, para uma análise acadêmica, podemos selecionar alguns fatores mencionados pelos diversos autores e classificá-los conforme a Figura 3.

\begin{tabular}{ll} 
Fatores & Aspectos correspondentes \\
\hline Econômicos & Demanda potencial; densidade de tráfego; tarifas; índice de aproveitamento. \\
Sociais & $\begin{array}{l}\text { Perfil dos passageiros (idade, renda, profissão etc.); comportamento dos } \\
\text { passageiros (por exemplo, preferência por determinado tipo de aeronave), } \\
\\
\text { relacionamento responsável com stakeholders. }\end{array}$ \\
Turísticos & $\begin{array}{l}\text { Vocação e tipo de turismo; oferta turística; tempo de permanência; ciclo de } \\
\text { vida do destino; sazonalidade. }\end{array}$ \\
Operacionais & $\begin{array}{l}\text { Frota; infra-estrutura aeroportuária (pista, slots, gates); pessoal (tripulação, } \\
\text { agentes, atendentes, despachantes etc.). }\end{array}$ \\
Geográficos & Distância; localização; relevo do destino operado; fatores climáticos. \\
Políticos & $\begin{array}{l}\text { Injunções de lideranças políticas municipais e estaduais; regulamentação } \\
\text { (políticas de liberalização do transporte aéreo). }\end{array}$ \\
Mercadológicos & $\begin{array}{l}\text { Concorrência (de outras empresas e de outros modos de transporte); } \\
\text { imagem; publicidade; propaganda. }\end{array}$
\end{tabular}

Figura 3. Fatores influenciadores do planejamento de linhas aéreas e seus aspectos correspondentes

Todos esses fatores influenciadores são importantes para as empresas aéreas em função dos elevados custos em que elas normalmente incorrem. A necessidade de minimizar a incerteza em relação ao sucesso da operação do serviço aéreo passa a ser um dos aspectos mais importantes que uma empresa aérea precisa levar em consideração. Um dos possíveis caminhos para a garantia de sustentabilidade de linhas aéreas regulares regionais é uma maior integração com toda a cadeia produtiva do turismo, que é o conjunto de atividades articuladas desde os insumos até a comercialização e distribuição do produto turístico final, composta por organizações como agências de viagens, operadoras turísticas, hotéis, empresas de eventos, transportadoras turísticas, entre outras.
Sob a ótica do planejamento de suas operações, é salutar considerar as possibilidades que a atividade turística pode carrear nas estratégias organizacionais das empresas de aviação. Não se trata aqui de perda do foco dessas companhias, que deve continuar sendo o de "transportar passageiros", mas de uma aproximação maior com a cadeia produtiva do turismo, a fim de ampliar o leque de possibilidades dos serviços dessas organizações. Portanto, sem o conhecimento prévio da importância do turismo para o setor de transporte, o planejador de transportes e os tomadores de decisão muitas vezes limitam seus objetivos a atender exclusivamente às necessidades de seu próprio setor, desconsiderando todo o impacto que a regulamentação ou o investimento em infra-estrutura pode acarretar a outras atividades, notadamente o comércio e o turismo (Forsyth, 2001; Pender, 2001; Wheatcroft, 1994, apud Palhares, 2002).

Em se tratando de ligações aéreas que envolvam destinos turísticos, há que se levar em consideração quais aspectos inerentes à atividade turística podem influenciar o planejamento de linhas aéreas. Segundo Beni (2001), a demanda por turismo apresenta especificidade própria, conforme as diversas motivações, necessidades e preferências dos turistas pelo produto permanente ou eventual, que imprime ao núcleo receptor sua vocaçāo turística e seu conseqüente poder de atração, permitindo-lhe uma afluência autodeterminada ou dirigida. Daí decorrem vários tipos de turismo. $\mathrm{O}$ autor destaca 35 tipos diferentes, dentre os quais: climático e hidrotermal, cultural, religioso, desportivo, científico, empresarial ou de negócios, familiar, de terceira idade, eventos, aventura, de incentivos, educacional, saúde, ecológico, jogo ou cassino.

No Brasil, diferentes tipos de turismo têm gerado fluxos específicos de viajantes a muitos municípios. O Instituto Brasileiro de Turismo - EMBRATUR, por intermédio da Deliberação Normativa 432, de 28 de novembro de 2002, destaca a existência de duas categorias diferenciadas de municípios turísticos no Brasil, baseadas em conjuntos de fatores e em variáveis abrangentes de características físico-geográficas, histórico-culturais e econômicas, a saber:

- Municípios Turísticos (MT) - São aqueles consolidados, determinantes de um turismo efetivo, capaz de gerar deslocamentos e estadas de fluxo permanente;

- Municípios com Potencial Turístico (MPT) - São aqueles possuidores de recursos naturais e culturais expressivos, encontrando no turismo diretrizes para o seu desenvolvimento socioeconômico.

Essa categorização tem levado à identificação de um total de 375 MTs e de 1.456 MPTs no Brasil. 
Outro aspecto fundamental de influência é a oferta turística local e regional, entendida aqui como o conjunto de equipamentos, bens e serviços de alojamento, alimentação, recreação e lazer, de caráter artístico, cultural, social ou de outros tipos, capaz de atrair e determinar o tempo de permanência de um público visitante. O tempo de permanência muito longo dos turistas no destino pode sinalizar à empresa aérea que eles se utilizam poucas vezes desse transporte, ao longo, por exemplo, de um ano, sendo que estadas mais curtas podem significar maior freqüência de idas e vindas de turistas.

Também pode influenciar o planejamento de linhas o ciclo de vida do destino turístico em termos de atratividade da demanda. Como qualquer outro produto, o destino turístico apresenta diferentes fases na sua evolução, segundo Butler (1980), podendo estar em exploração, envolvimento das autoridades locais, desenvolvimento, consolidação, parada e declínio ou renovação. Ao planejador de transporte cabe saber em qual fase do ciclo de vida encontram-se os destinos turísticos envolvidos na sua malha, pois o fluxo de pessoas será diferente em cada um deles e, conseqüentemente, afetará o correto dimensionamento e adequação do transporte.

Outro aspecto influenciador do planejamento é a sazonalidade. É minimamente prudente observar o comportamento dos fluxos turísticos ao longo do ano e identificar quais são os períodos considerados de alta e baixa temporada. A sustentabilidade da linha a ser operada pode depender da acurabilidade dessa interpretação. $\mathrm{Na}$ alta temporada são observados todos os problemas de saturação de uma grande demanda, com a resposta de uma elasticidade muito fraca na oferta correspondente (de transporte aéreo, por exemplo); na baixa temporada, pelo contrário, ocorrem os derivados de uma demanda fraca, com a rigidez de uma oferta de transportes. A sazonalidade, portanto, pode produzir um desequilíbrio na demanda de transporte aéreo no destino turístico (Montejano, 2001). Na conjunção dos aspectos apontados é que se poderá ter um melhor planejamento de horários, dias, freqüências e o tamanho mais adequado de aeronaves.

\section{Metodologia}

O presente estudo é, essencialmente, de três tipos: exploratório, descritivo e indutivo. Exploratório, pois estuda fatores influenciadores do planejamento de empresas aéreas que não apresentam um sistema de teorias e conhecimentos desenvolvidos. É também do tipo descritivo, pois descreve os fatores de influência utilizados no processo de planejamento e implantação de linhas aéreas regulares das empresas pesquisadas. Indutivo porque, após a análise dos dados, propõe a criação de um modelo para o planejamento de linhas aéreas regionais no Brasil.

$\mathrm{O}$ universo da pesquisa foi aquele composto pela totalidade de empresas aéreas de atuação regional no Brasil durante o ano de 2003. Como foram identificadas apenas dez empresas com esse perfil, a amostra selecionada coincidiu com o universo.

Após a realização de levantamento bibliográfico/documental e de três etapas de pré-testes, foram enviados os questionários definitivos a cada uma das empresas. Contatos prévios foram feitos, entre maio e julho de 2003, por telefone, com as diretorias comerciais - setor apontado nos pré-testes como o mais adequado - de cada empresa, a fim de garantir um melhor encaminhamento, além de prestar algumas informações preliminares acerca dos objetivos da pesquisa. $\mathrm{O}$ envio dos questionários foi realizado por meio de correio eletrônico (e-mail), entre agosto e outubro de 2003, diretamente para os diretores identificados e contatados previamente.

Dos dez questionários enviados, obteve-se um retorno de cinco. Os dados coletados foram transcritos em planilhas e representados em forma de gráficos (ver Figuras 4 a 7) como uma maneira de realizar uma análise de distribuição porcentual das respostas.

\section{Análise dos dados coletados}

\section{Perfil geral das empresas aéreas regionais}

O perfil das empresas aéreas regulares regionais pôde ser levantado por meio de consultas realizadas no DAC, nos websites das empresas e em revistas especializadas do setor (dados secundários), além de parte dos questionários respondidos pelas próprias empresas (dados primários). Tal levantamento apontou algumas características em relação às dez empresas aéreas regionais em operação em 2003.

A grande maioria das atuais empresas aéreas regionais iniciou operações em vôos regulares há relativamente pouco tempo. A data mais antiga é de 1993, sendo que as demais começaram a operar na segunda metade da década de 1990. Esse dado coaduna com a realidade gerada pelo processo de flexibilização ocorrido no mesmo período, resultando numa maior entrada de empresas no setor (ver Figura 1). Outro fato observado diz respeito à concentração de empresas na Amazônia Legal e na região Nordeste (ver Tabela 1). Isso pode ser decorrência de dois fatores principais. O primeiro, pelo incentivo da suplementação tarifária, uma 
vez que modestamente aplicado, só continua beneficiando as linhas operadas nessas regiões. O segundo, de ordem geográfica, uma vez que é nessas regiões onde esse tipo de transporte enfrenta menos concorrência por parte dos demais modos de transportes, seja pela precariedade de infra-estrutura, seja pelas suas grandes extensões territoriais (BNDES, 2002).

Quanto ao número de cidades atendidas, o que se tem observado é uma grande variação do número de localidades servidas por cada empresa aérea. Além disso, notou-se, durante as várias consultas realizadas ao longo da pesquisa, a entrada e saída de localidades da "malha aérea" das companhias, isto é, num período de tempo de aproximadamente seis meses, o número de cidades servidas variou consideravelmente. Essa oscilação entre ativar e desativar linhas pode revelar mais do que opções de tentativa ou um reflexo da crise do setor: pode estar embutindo falhas de gestão e planejamento das empresas regionais.

Confrontando os dados referentes ao número de cidades atendidas por empresas aéreas e verificando como esses municípios são categorizados pela EMBRATUR, pôde-se elaborar a Tabela 1. Observa-se que o número total de municípios atendidos, descontados aqueles que se repetem entre as empresas, é de apenas 94 . Número bastante reduzido, que representa apenas $1,7 \%$ dos municípios existentes no país. Já ao verificar-se a quantidade de municípios turísticos servidos por linha regular, chega-se a 13,6\% do total existente no Brasil, valor este razoavelmente representativo e que, portanto, deveria elevar o peso da importância que as empresas regionais dão ao turismo como fator de influência nos seus planejamentos e decisões. Essa importância fica ainda mais clara quando se nota que a soma dos municípios turísticos (51) e potencialmente turísticos (14) atendidos pelas empresas aéreas regionais corresponde a $69 \%$ dos destinos por elas operados.

Comparando a evolução do número de cidades atendidas pelas empresas aéreas regionais com o número de municípios existentes no Brasil, elaborou-se a Tabela 2. Os dados mostram que, em termos de quantidade de localidades atendidas por vôos regulares, houve um grande retrocesso nos últimos 43 anos, uma diminuição de três vezes (da ordem de 300 para 94 - ver também Figura 1). Isso é mais agravado quando se observa que, no mesmo período, a população e o número de municípios existentes no país mais que dobrou.

\section{O disparo do processo de planejamento de linhas}

A pesquisa de campo apontou que as empresas aéreas que responderam à pesquisa normalmente possuem um setor específico denominado "planejamento de linhas", tendo o mesmo caráter mais técnico e operacional. Nesse setor são
Tabela 1. Número de cidades turísticas servidas pelas empresas regionais

\begin{tabular}{llccc}
$\begin{array}{l}\text { Empresas } \\
\text { aéreas }\end{array}$ & $\begin{array}{c}\text { Região } \\
\text { de atuação }\end{array}$ & $\begin{array}{c}\text { Municípios } \\
\text { atendidos }\end{array}$ & $\begin{array}{c}\text { MT } \\
\text { atendidos }\end{array}$ & $\begin{array}{c}\text { MPT } \\
\text { atendidos }\end{array}$ \\
\hline ABAETÉ Linhas Aéreas & $\begin{array}{l}\text { Nordeste } \\
\text { META - Mesquita Transportes Aéreos }\end{array}$ & 4 & 2 & 1 \\
$\begin{array}{l}\text { Amazônia } \\
\text { Sul, Sudeste } \\
\text { e Nordeste }\end{array}$ & 10 & 5 & 0 \\
PANTANAL Linhas Aéreas & SP, MG, MS, BA & 10 & 24 & 0 \\
PENTA-PENA Transportes Aéreos & Amazônia & 4 & 4 & 3 \\
PUMA AIR & Amazônia & 6 & 3 & 0 \\
RICO Linhas Aéreas & Amazônia & 25 & 5 & 1 \\
TAVAJ Transportes Aéreos & Amazônia & 11 & 5 & 6 \\
TOTAL Linhas Aéreas & MG & 10 & 8 & 1 \\
TRIP - Transporte Regional & PR, SP, MT, & 12 & 9 & 2 \\
$\quad$ do Interior Paulista & Nordeste & & & \\
\hline Soma Total & & 121 & 68 & 17 \\
\hline Municípios distintos & & 94 & 51 & 14 \\
Total de municípios no Brasil & & 5.561 & 375 & 1.456 \\
Porcentual do total de municípios no Brasil & $1,7 \%$ & $13,6 \%$ & $0,96 \%$ \\
\hline
\end{tabular}

Legenda: MT - Municípios Turísticos; MPT - Municípios Potencialmente Turísticos.

Fontes: EMBRATUR, IBGE e sites das empresas (consultado em 18 out. 2003).

Tabela 2. Municípios existentes e municípios atendidos por vôos regionais

\begin{tabular}{cccc} 
Ano & $\begin{array}{c}\text { População } \\
\text { do Brasil }\end{array}$ & $\begin{array}{c}\text { Municípios } \\
\text { existentes no Brasil }\end{array}$ & $\begin{array}{c}\text { Municípios atendidos } \\
\text { por vôos regionais }\end{array}$ \\
\hline 1960 & 70 milhões & 2.766 & cerca de 300 \\
2003 & 175 milhões & 5.561 & 94 \\
\hline
\end{tabular}

Fontes: Websites do DAC, da EMBRATUR e do IBGE. 
analisados fatores como: melhor utilização da frota, possibilidade de rotas no sistema, custos, rentabilidade da linha, pessoal necessário e possíveis escalas. No entanto, quando se trata do disparo do processo de planejamento, ficou evidente que, na maioria das empresas respondentes (83\%), este é de responsabilidade do setor comercial.

Tal resultado indica que o setor comercial fica atento a possíveis oportunidades de mercado (exemplo: concorrência pública, interesse comercial na localidade, fluxo de turistas a negócios e lazer) e, ao identificá-las, solicita ao setor de "planejamento de linhas" que proceda a estudos preliminares de viabilidade operacional. Por conta disso, a empresa tem sempre diversos estudos prontos, aguardando uma melhor oportunidade, tais como quando ocorre a ampliação de uma pista de pouso/decolagem, ou por causa da impossibilidade de continuar operando determinada linha, gerando a necessidade de iniciar outra.

\section{Peso dos fatores influenciadores, o fator turístico e respectivos aspectos relacionados}

Observa-se, nas respostas dadas aos fatores influenciadores no processo de planejamento de linhas (ver Figura 4), que as empresas pesquisadas estão considerando de forma destacada os fatores econômicos (33\%) e operacionais (15\%), com seus respectivos aspectos. As respostas demonstram haver um reconhecimento de todos os fatores influenciadores detectados na revisão bibliográfica (ver Figura 3). No entanto, às vezes, podem estar apenas explicitando um reconhecimento formal e não revelando estudos mais aprofundados para avaliar o impacto de cada um deles, com exceção talvez do fator econômico. É interessante notar que

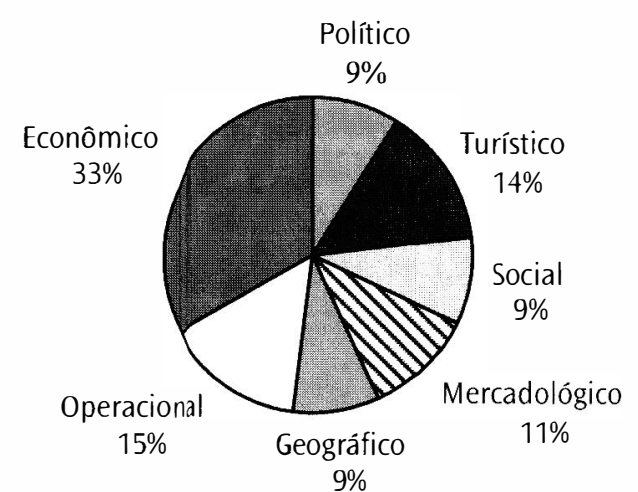

Figura 4. Peso comparativo dos fatores de influência no planejamento de linhas aéreas o peso atribuído ao fator turístico (14\%) é quase tão representativo quanto o peso dado ao fator operacional, indicando uma preocupação considerável com a influência dos seus aspectos no planejamento de linhas regulares, o que ensejaria mais estudos por parte das empresas a respeito desse fator. $O$ pequeno peso atribuído ao fator político parece não estar em consonância com o referencial teórico, pois nele se aponta para uma influência expressiva desse fator, no Brasil, via regulamentações e subsídios, por exemplo. Além disso, o fator político foi apontado pelas empresas como um dos principais entraves ao desenvolvimento do setor.

Em relação aos segmentos de atuação das empresas aéreas, a Figura 5 mostra o porcentual médio de participação desses segmentos nas empresas da amostra. Ela revela que as empresas aéreas buscam atender, de maneira diferenciada, a quatro segmentos simultaneamente: participação no mercado de cargas (23\%), viajantes a negócios (52\%), lazer (18\%) e fretamentos (7\%). A justificativa para essa diversificação pode residir no fato de que, quando um determinado segmento está ruim, um ou mais segmentos podem compensar uma dificuldade momentânea. Como exemplo disso, pode-se citar a sazonalidade do final de ano, quando o movimento de executivos diminui, porém aumenta o fluxo de viajantes a lazer. A análise também demonstra que os turistas são incluídos tanto entre os viajantes a lazer como a negócios constituindo um relevante segmento para as empresas aéreas. Também chama atenção a importância atribuída ao transporte de carga, que chega a ser bastante superior à importância dada a fretamentos (normalmente feito para transporte de passageiros), sinalizando que, para viabilizar seus negócios, as empresas aéreas regionais, bem como grande parte das empresas de transportes, precisam complementar no segmento de carga uma fonte importante de receita.

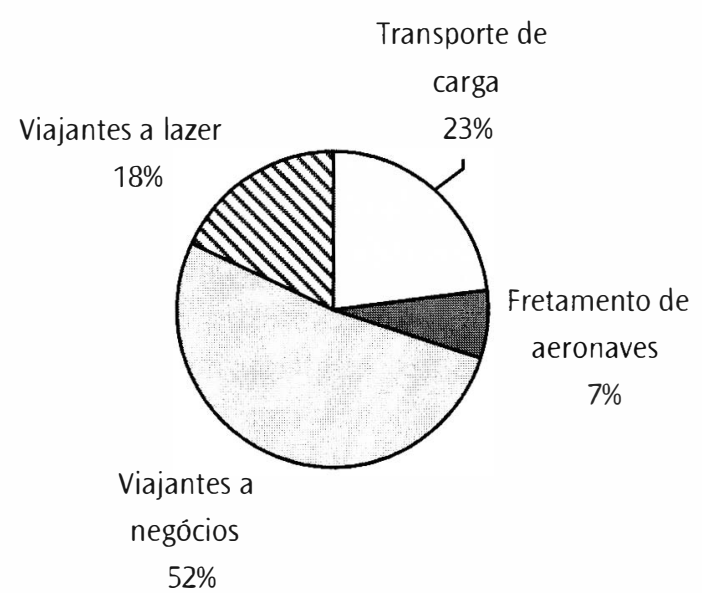

Figura 5. Divisão dos mercados de atuação das empresas regionais 
No que diz respeito às características do fator turístico que as empresas aéreas regionais levam em consideração no planejamento de linhas regulares, a Figura 6 aponta o "tipo de turismo" praticado nos destinos (lazer, negócios etc.), a "infra-estrutura turística do destino"e a sazonalidade como as mais importantes. É interessante notar que aspectos, tais como o "tempo de permanência dos passageiros" e o "ciclo de vida do destino", são pouco considerados durante o processo de planejamento de linhas que envolvam cidades turísticas.

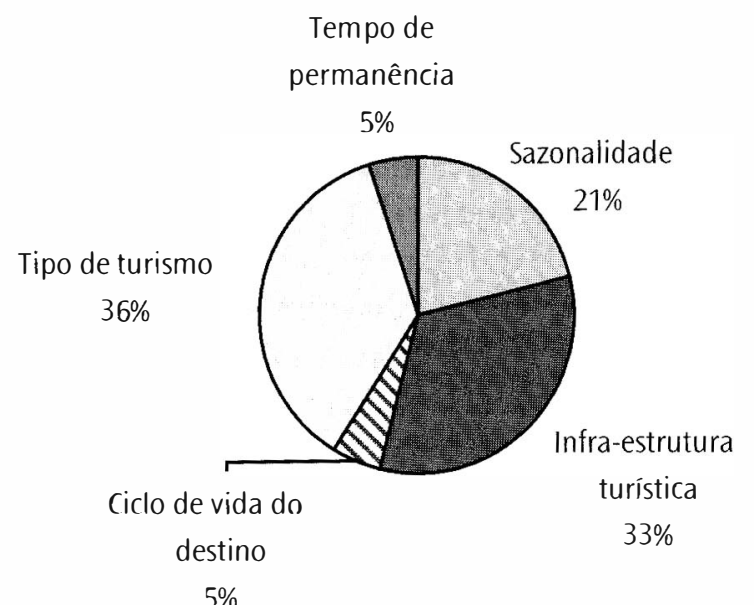

Figura 6. Peso dos aspectos turísticos no planejamento de linhas aéreas regulares

Dentre os segmentos específicos do turismo com que as empresas buscam parcerias para viabilizar novas linhas (ver Figura 7), é de se notar a grande ênfase dada aos agentes de viagem, que são responsáveis apenas pela venda de passagens. Já os operadores turísticos, cujo papel na elaboração, implementação e venda de pacotes turísticos pode ser preponderante na escolha do destino turístico, e conseqüentemente do tipo de transporte e empresa a ser contratada, tiveram a mesma importância dos organizadores de eventos. Talvez isso esteja relacionado ao alto porcentual de viajantes a negócios, conforme indicado na Figura 5. Faz-se mister enfatizar também o papel das secretarias de turismo, uma vez que estas, com o poder político que lhes é inerente, têm condiçōes de incentivar e intermediar os diversos atores (transporte e turismo) no destino. De certa forma, essa resposta não corresponde ao que foi verificado na Figura 4, em que o peso político foi um dos menos relevantes.

Por fim, é necessário considerar os principais entraves para o início e a viabilização de novas linhas aéreas, de acordo com a opinião das empresas aéreas.

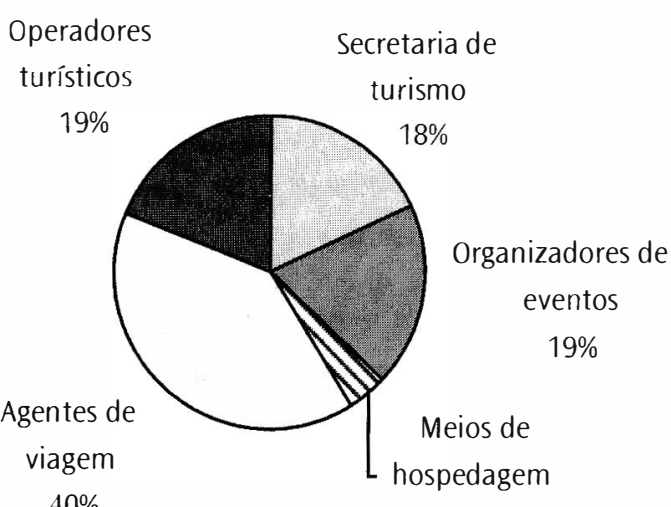

$4 \%$

Figura 7. Peso dos segmentos turísticos na implantação de linhas aéreas

Nessa questão, houve praticamente consenso por parte das empresas respondentes, pois quase todas fizeram referência, de uma maneira ou de outra, aos seguintes problemas: alto custo operacional envolvido (insumos produtivos); dificuldades da política econômica do país; grande vulnerabilidade quanto à variação cambial; baixo poder aquisitivo da população; infra-estrutura inadequada; dificuldade de acesso a financiamentos; falta de uma política definida para o setor; e, por fim, excesso de impostos.

As respostas fornecidas deixam transparecer uma relação com os fatores de influência no ambiente econômico, operacional, social e político. Os problemas enfrentados pelas empresas reforçam a importância do reconhecimento da influência que tais fatores exercem sobre suas estratégias na abertura de linhas regulares. No entanto, os entraves apontados parecem remeter às dificuldades mais para o lado de "fora" das empresas, ou seja, ao seu ambiente externo, o que em certa medida evidencia a realidade enfrentada pela maioria das empresas aéreas regionais. Porém, vale a pena ressaltar que não indicaram nenhum entrave do ponto de vista do ambiente interno, notadamente de gestão e planejamento. E os óbices apontados são razōes ainda mais fortes para minimizar erros de planejamento interno da organização.

Ao reconhecer a falta de uma política mais definida para o setor como um importante entrave para a implantação de linhas aéreas regulares, evidenciou-se certa discrepância com a questão anterior, sobre o peso atribuído ao fator político (9\%) de influência (vide Figura 4). Talvez o fator político não tenha um peso tão pequeno assim, levando-se em consideração aqui também a presença do governo, ora com medidas mais flexibilizantes e menos intervencionistas, ora, como em 2003, retrocedendo para um modelo regulatório mais ativo. 


\section{Considerações finais}

Elaborou-se, a partir das respostas das empresas entrevistadas, um modelo esquemático representativo do processo de planejamento de linhas, conforme a Figura 8.

O conceito de estratégia apresenta componentes de planejamento e de tomada de decisão. O disparo do processo começa com uma solicitação de linha que pode ocorrer no ambiente externo ou interno da empresa (geralmente por iniciativa do setor comercial). Notadamente, no ambiente externo da empresa, encontram-se fontes de análise para revelar quais são efetivamente os fatores que podem influenciar o planejamento de linhas. Como esses fatores são variados, as empresas realizam uma seleção dentre os mais apropriados em um determinado

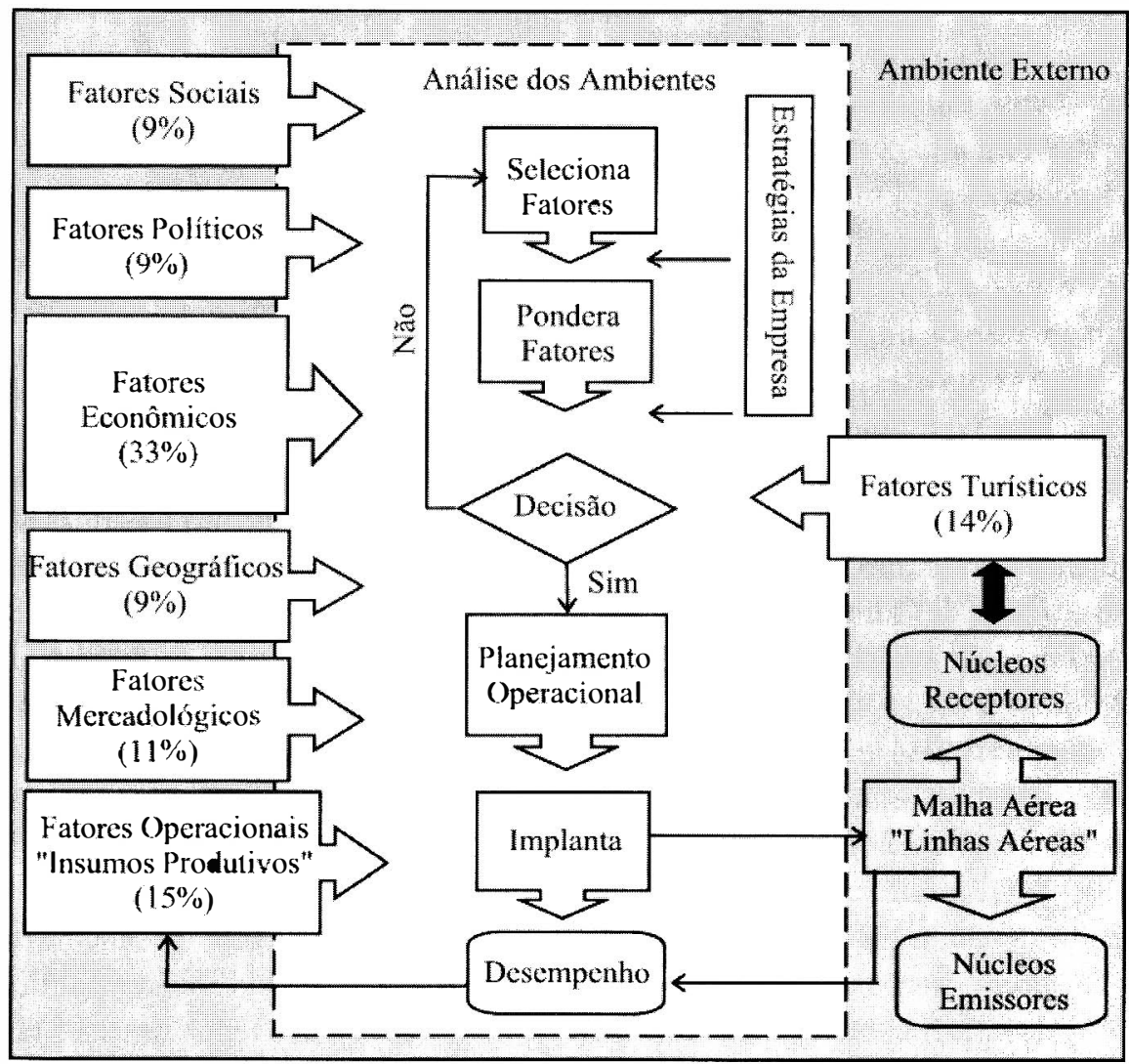

Figura 8. Fluxograma do processo de planejamento e decisão de implantação de linhas aéreas período e que reflitam seus objetivos estratégicos. Mediante as estratégias da empresa, os fatores são ponderados, pois alguns exercem peso maior que outros e, portanto, uma influência mais acentuada na decisão.

Observa-se que alguns fatores têm maior peso no ambiente interno da empresa. Isso se dá por conta do peso a eles atribuído e a alguns aspectos pertencentes à empresa, como, por exemplo, os insumos produtivos (frota e recursos humanos), que estão intimamente ligados à tarefa de planejamento operacional. Os stakeholders internos (colaboradores e acionistas) também apresentam aspectos relacionados ao fator social que ocupa o ambiente interno da empresa. Após a ponderação, a decisão estará num maior grau de certeza e pronta para alimentar a etapa seguinte, que é o planejamento técnico e operacional das linhas a serem implantadas. Caso a decisão aponte para a não implantação naquele determinado momento ou para aquela linha específica, a informação realimenta o processo ao seu início.

Os insumos produtivos da empresa (frota e pessoal), além dos objetivos estratégicos, exercem uma participação mais direta no planejamento operacional da linha. Uma vez devidamente planejadas, as linhas são implantadas e passam a fazer parte da malha aérea.

Por fim, o desempenho da malha aérea opera, como visto no modelo de Fryszman (1990), parâmetro de controle e realimentação do modelo, uma vez que a empresa fixa metas de participação de mercado e lucro que, não sendo atingidas, exigirão revisão de sua estratégia de atuação. Até mesmo a lucratividade é um aspecto gerador de capital necessário à aquisição de recursos e à expansão das atividades, dentro de uma conjuntura de mercado favorável. Ademais, todos os fatores estabelecem uma relação de mútua influência e dependência entre si e com os pólos emissores-receptores das linhas aéreas.

Além da descrição do processo de planejamento das empresas pode-se, ainda, fazer as seguintes considerações:

- O planejamento de linhas aéreas regulares possui aspectos relacionados à administração estratégica das empresas aéreas regionais;

- A ocorrência e importância dadas ao fator de influência turístico, com seus respectivos aspectos, ainda que meramente formais, indicam a relevância da pesquisa no estudo da interface transporte aéreo e turismo;

- O planejamento, implantação e manutenção de linhas regulares contam com a participação efetiva de outros segmentos da cadeia produtiva do turismo, não ocorrendo, entretanto, a tão almejada integração na qual as empresas aéreas regulares regionais brasileiras são atores importantes; 
- As empresas aéreas regionais vivem um momento de grande oportunidade de mercado, pois as grandes companhias de aviação deixaram de atender a várias a localidades de pequeno e médio porte, abrindo espaço para as empresas regionais atuarem;

- O fator político aponta para o fim da complementação tarifária, exigindo com isso melhor planejamento das linhas do que até então era feito;

- O governo sinaliza novamente com tendências regulamentárias mais fortes, aumentando o viés político nas decisões. A proteção em forma de monopólio, oligopólio, além dos subsídios de mercado, pode ser uma vantagem por um lado, quando se olha para as empresas atualmente em operação e as barreiras de entrada que serão criadas; no entanto, verificando por outro prisma, pode ser um esconderijo perigoso para as ineficiências de gestão das empresas que já demonstram debilidades nesse quesito.

Exemplo do que foi exposto neste artigo é que com a criação, pelo Ministério do Turismo, do chamado "Programa Roteiros do Brasil", em que se prevê a implementação de 108 pólos turísticos no país, buscou-se adaptar o Plano Aeroviário Nacional às necessidades dessa proposta. Para tanto foi necessária a participação do Instituto de Aviação Civil, ligado ao DAC (Ministério do Turismo, 2004).

O presente estudo, longe de esgotar o assunto, resultou numa primeira aproximação do perfil atual do setor de transporte aéreo regional brasileiro, com suas respectivas estratégias de planejamento de linhas e o turismo. Cabe ressaltar, no entanto, que os resultados aqui apresentados valem tão somente para as empresas que responderam à pesquisa, não devendo ser extrapolados para as demais, apesar da razoável representatividade obtida. Pesquisas futuras poderão identificar similaridades ou não em outras esferas, tais como as empresas que operam linhas de âmbito nacional.

\section{Referências bibliográficas}

ATA. 2001. The airline handbook (Air Transport Association). Agosto. BENI, M. C. 2001. Análise estrutural do turismo. 4.ed. São Paulo: Senac.

BNDES. 2002. Aviação Regional Brasileira (Modal Aéreo IV). Banco Nacional de Desenvolvimento Econômico e Social. Rio de Janeiro.

BUTLER, R. W. 1980. The concept of the tourist area cycle of evolution: implications for management of resources. Canadian Geographer, v.24, n.1, p.5-12.
DEBBAGE, K. G. 2002. Airport runway slots. Annals of Tourism Research, v.29, n.4, p.933-951. DOGANIS, R. 2001. The airline business in the $2^{\text {Ist }}$ century. Londres: Routledge.

DONNE, M. 2001. Regional airlines: the European scene. Travel \& Tourism Analyst, v.2, p.3-14. FRYSZMAN, A. S. 1990. Sistema de apoio à decisão no planejamento de linhas aéreas: uma proposta para o mercado doméstico brasileiro de passageiros. Dissertação (Mestrado). Departamento de Engenharia de Transportes, Universidade de São Paulo, São Paulo.

GRAHAM, B. 1997. Regional airline services in the liberalized European Union single aviation market. Journal of Air Transport Management, v.3, n.4, p.227-238.

\& GUYER, C. 2000. The role of regional airports and air services in the United Kingdom. Journal of Transport Geography, v.8, p.249-262.

HANLON, J.P. 1992. Regional air services and airline competition. Tourism Management, v.13, n.2, p.181-195.

MINISTÉRIO do Turismo. 2004. Termo de referência. Ministério do Turismo. Brasília. MONTEJANO, J. 2001. Estrutura do mercado turístico. São Paulo: Roca.

PALHARES, G. L. 2001. Transporte aéreo e turismo: gerando desenvolvimento socioeconômico. São Paulo: Aleph.

2002. Transportes turísticos. São Paulo: Aleph.

SCHÄFFLER, J. 1995. Regional aircraft. In: SPON, E. F. (Ed.). Passenger transport after $2000 \mathrm{AD}$. Londres: Royal Socicty. p.145-161

SILVA, W. P., L. S. Portugal et al. 2000. Sistema integrado de informaçōes geográficas e técnicas de alocação para análise da demanda por transporte aéreo de passageiros. Xı Congresso Pan-americano de Engenharia de Trânsito e Transporte. Gramado: ANPET, p.263-275.

SILVEIRA, J. A. 2003. Transporte aéreo regular no Brasil: análise econômica e função de custo. Dissertação (Mestrado). Programa de Pós-Graduação em Engenharia, Universidade Federal do Rio de Janeiro, Rio de Janeiro.

TRIGO, L. G. G. 2000. Viagem na memória: guia histórico das viagens e do turismo no Brasil. São Paulo: SEnAC.

Recebido em 24/06/2004 (1 ${ }^{\text {a }}$ versão) e 17/10/2004 (2a versão) Aprovado em 19/10/2004. 